Philosophy and Phenomenological Research

Vol. XCV No. 3, November 2017

doi: 10.1111/phpr.12441

(C) 2017 Philosophy and Phenomenological Research, LLC

[Correction added on 13 March 2018, after first online publication: Online open removed retrospectively.]

\title{
The Defeasibility of Knowledge-How
}

\author{
J. ADAM CARTER
}

University of Glasgow

JESÚS NAVARRO

University of Seville

\begin{abstract}
Reductive intellectualists (e.g., Stanley \& Williamson 2001; Stanley 2011a; 2011b; Brogaard 2008; 2009; 2011) hold that knowledge-how is a kind of knowledge-that. If this thesis is correct, then we should expect the defeasibility conditions for knowledge-how and knowledge-that to be uniform-viz., that the mechanisms of epistemic defeat which undermine propositional knowledge will be equally capable of imperilling knowledge-how. The goal of this paper is twofold: first, against intellectualism, we will show that knowledge-how is in fact resilient to being undermined by the very kinds of traditional (propositional) epistemic defeaters which clearly defeat the items of propositional knowledge which intellectualists identify with knowledge-how. Second, we aim to fill an important lacuna in the contemporary debate, which is to develop an alternative way in which epistemic defeat for knowledge-how could be modelled within an anti-intellectualist framework.
\end{abstract}

\section{Propositional Knowledge and Epistemic Defeat}

It is ubiquitous in mainstream epistemology to theorize about what properties should be regarded as upgrading epistemic status. For instance, we evaluate beliefs positively from an epistemic point of view in light of their being supported by evidence, issued by a reliable source, responsibly held, safe, sensitive, etc. ${ }^{1}$ Unsurprisingly, we are also interested in what might cause a belief to lose positive epistemic status. Defeasibiliy, as Michael Sudduth (2008) puts it, refers to a 'belief's liability to lose some positive epistemic status, or to having this status downgraded in some particular way. ${ }^{2}$ There are various ways this can happen, and accordingly, various kinds of epistemic defeaters, viz., where an 'epistemic defeater' is shorthand for: some condition which actualizes the potential of an epistemic state to be downgraded in status.

1 For discussion on the kinds of considerations which frame evaluation from an epistemic point of view, see, for example, Alston (2005); Goldman (1999) and Sosa (1991).

2 Just as knowledge asymmetrically entails epistemic justification, so correlatively, if the obtaining of some condition defeats the status of a belief as epistemically justified, this asymmetrically entails the defeat of the status of that belief as knowledge. 
The simple picture of epistemic defeat that is standard in contemporary literature (e.g., Pollock and Cruz $1986^{3}$ ) is one in which the nature of epistemic defeaters is propositional in character, and mostly applied to cases of so-called 'knowledge-that' (typically, by undermining the justification component of knowledge-that). On this traditional picture, both what is defeated (the piece of presumed knowledge) as well as what produces the defeat (the defeater itself) are propositional states related by their truth conditions. On this assumption, the standard model makes (at least) two fundamental distinctions. According to the first one, defeaters may be psychological or normative, depending on whether the potential of an epistemic state to be downgraded is actualised (i) in virtue of some belief that is actually being held by the agent (in the case of psychological defeaters), or (2) in virtue of some belief that the agent should have (in the case of normative defeaters). ${ }^{4}$ According to the second distinction (e.g., Pollock \& Cruz 1986, 193), the defeater may either operate by rebutting or by undercutting a the knowledge/justification of a belief, depending on whether (i) it furnishes new evidence against the target belief (in the case of rebutting defeaters) or (2) it undermines the evidence the agent had in its favour (in the case of undercutting defeaters). ${ }^{5}$

Some brief examples will be helpful here. Let's consider, first, psychological defeaters, alternatively known as mental-state defeaters, which are doubts or beliefs which, when they defeat propositional knowledge, they do so in virtue of simply being had, regardless of whether they are true, justified, etc. For example, to use a straightforward case from Pollock \& Cruz $(1986,43)$, suppose you see a book that appears red and accordingly judge that it is red. Someone then tells you that it is in fact not red, and you trust their word. In such a case, regardless of whether this person is lying to you, in such a circumstance, you acquire a psychological defeater of what Pollock \& Cruz call a rebutting variety; your justification/knowledge for your belief that the book is red is defeated by the new belief you acquire (that it is not red) specifically by counting against the truth (i.e., by rebutting) of the target proposition.

Psychological defeaters can also defeat propositional knowledge in a way that is undercutting rather than rebutting - viz., by indicating that the agent's belief that $p$ was unreliably or otherwise defectively formed. Pollock and Cruz offer an undercutting variation on the red book case as follows: just suppose you believe you're looking at a red book but then come to hear not that the book is not red, but rather, that there is red lighting in the room. This new information causes you to doubt that the way you formed the believe (i.e., via perception in a local environment with distorted light) will likely give you a true belief on this occasion.

Normative defeaters (e.g., Lackey 2014, 292) by contrast with psychological defeaters, are those doubts and beliefs that defeat propositional justification/knowledge in virtue of being beliefs which one (epistemically) should have (whether or not one does have them), and which either count against the truth of the target proposition, in the rebutting case, or against the reliability of the formation of the target proposition, in the undercutting case. ${ }^{6}$

For an early presentation of this kind of distinction, see Pollock (1970).

$4 \quad$ We are here following Lackey's latest formulation $(2014,292)$, which differs from her own earlier terminology $(1999 ; 2005)$. Note that some philosophers refer to normative defeaters, in Lackey's sense, as propositional defeaters. We are, however, following Lackey in reserving 'propositional' in this paper to pick out the wider system of epistemic defeat which encompasses both psychological (i.e., mental state) and normative defeaters. As will be relevant for our purposes, these are propositions which one does belief, and propositions which one should believe.

$5 \quad$ Pollock \& Cruz (1986, 196). See here also Bergmann (1997; 2005).

6 For a helpful recent discussion of the epistemic 'should' in cases where we claim an agent should (epistemically) have believed something or known something, see Goldberg (2015). Cf. Chrisman (2008). 
To illustrate normative (i.e., non-psychological) defeat, we can simply run some variations on Pollock \& Cruz's red book case. Just suppose that, after the individual tells you that the book is not red, you stubbornly continue to believe that it is red, despite supposing that the individual who told you this was a very reliable source. Here, you don't $a c$ tually acquire a belief that the book is not red, so you do not uptake any propositional attitude that indicates the target proposition is false. But, in this case, there is a belief (viz., that the book is not red) you (epistemically) should have such that, if you had it, it would count against the truth of the target proposition. This is a normative rebutting defeater. By contrast, an undercutting normative defeater by contrast is a belief you epistemically should have which counts against the reliability of the formation of the target belief; for example, if you are told by a reliable source that there is red lighting in the room, but continue to believe nonetheless that the book is red, you will have acquired a normative undercutting defeater for the target proposition.

There are of course many aspects of defeasibility that aren't settled, ${ }^{7}$ though the above picture captures, in ways that are largely orthodox and uncontentious, how propositional knowledge might be downgraded in epistemic status through ordinary mechanisms of epistemic defeat. With this simple picture in mind, let's now move to the specific issue of how knowledge-how might subject to being downgraded in epistemic status.

\section{Intellectualism and Anti-Intellectualism}

The idea that knowing-how and knowing-that are different kinds of epistemic states had been widely undisputed since Gilbert Ryle $(1946 ; 1949)$ made this distinction explicit in the mid-twentieth century. Ryle called 'intellectualism' the attempt to consider that knowing how to $\varphi$ consists in knowing that something is the case, and he claimed that such a view was doomed to fail, since it would be committed either to an infinite regress or to the postulation of impossible mediators between theory and practice. ${ }^{8}$

In contrast to the intellectualist's identification of knowing-how with knowing-that, Ryle insisted that knowing-how has much more to do with our abilities and capacities than with the grasping of true propositions, and that, in essence, knowing-how was not a propositional state. Knowing-how to $\varphi$, according to Ryle's perspective, is not principally a matter of grasping truths about the practice of $\varphi$-ing, but a matter of having the power to $\varphi$, the skill to $\varphi$ well, the ability to achieve success in $\varphi$-ing in the relevant circumstances, all of which are issues related to what we are able to do, and not of what propositional attitudes we endorse. ${ }^{9}$

Ryle's distinction between knowing-how and knowing-that was more or less uncritically accepted within mainstream epistemology prior to Stanley \& Williamson's (2001) influential attempt to motivate intellectualism on linguistic grounds. Stanley \& Williamson attempted to show in particular that knowing-how to $\varphi$ is, like knowing-what, knowingwhen, or knowing-why, just a matter of knowing a fact, and is thus a case of propositional knowledge. Take, for example, knowing-how to ride a bike. As Stanley puts it,

See Sudduth (2008).

8 See Stanley (2011, Ch. 1) for a recent critical discussion of Ryle's anti-intellectualist argument from regress. Cf., Cath (2013), Hornsby (2011) and Navarro (under review) for criticism of Stanley's interpretation of Ryle.

9 The issue of whether Ryle held himself a positive view that may be labelled as "anti-intellectualism", according to which states of know-how just are abilities is controversial—see Hornsby (2011) and Navarro (under review). 
[...] you know how to ride a bicycle if and only if you know in what way you could ride a bicycle. But you know in what way you could ride a bicycle if and only if you possess some propositional knowledge, viz. knowing, of a certain way $w$ which is a way in which you could ride a bicycle, that $w$ is a way in which you could ride a bicycle $(2010,209)$.

In short, the fact that one knows, when one knows how to $\varphi$ is, in their view, the answer to a question: 'how could you $\varphi$ ?', and knowing that answer is knowing that there is a way to $\varphi$, call it $w$, by means of which one would $\varphi$ successfully if one tried. Knowinghow, according to this new intellectualist and reductivist trend, may be reduced to a special case of propositional de se knowledge: knowledge about the way in which one could $\varphi^{10}$ - a way that must be grasped under what they call 'a practical mode of presentation'. ${ }^{11}$

We should expect that, if Stanley \& Williamson were right, and knowledge-how could be reduced to knowledge-that, it would be subject to the very same mechanisms of epistemic defeat as knowledge-that, along the lines we have sketched in the previous section. This is a natural extension of a point which Stanley (2011) himself grants explicitly. As he puts it, "[i]f knowing-how is a species of knowing that, the properties of knowing-that should be properties of knowing-how" (2015, 211), and this holds for specifically epistemological properties. $^{12}$

For example, Stanley admits that if Gettier cases can't be constructed for knowledgehow, then this would be a mark against intellectualism, given that Gettier cases are constructible (in the paradigmatic case) for knowledge-that. ${ }^{13}$ So, just as it would be a problem for the intellectualist if knowledge-how and knowledge-that differ in their respective compatibility with Gettier cases, likewise, it would be-by Stanley's own

10 Note that other forms of intellectualism (i.e., Bengson \& Moffett 2011b) have also been proposed, that do not intend to reduce knowledge-how to propositional states, but they will not be the focus of our attention here.

11 See Stanley (2011), along with Glick (2015) and Pavese (2015). Anti-intellectualists (e.g., Schiffer 2002; Nöe 2005; Carter \& Pritchard 2015c have in various places expressed dissatisfaction with the elusiveness of practical modes of presentation. See Pavese (2015) for an alternative construal of practical modes, as a way of supplementing intellectualism, according to which practical modes are 'conceptual components of the propositional content that is putatively known when one knows how to do something'. On Pavese's view, knowledge-how is knowledge of what she calls a practical proposition, which has, as a component, a practical sense $(2015,2)$.

12 Notice that this is only of application if, following Stanley \& Williamson, the intellectualist identifies knowledge-how with garden-variety knowledge-that, which includes many other features besides being propositional (e.g., being true, justified, believed by the agent, Gettier-proof, safe, ... or defeasible in some specific ways). There are weaker versions of intellectualism where it would not follow that anything that is a property of standard knowledge-that must also be a property of the specific sort of knowledge-that knowledgehow is supposed to be reduced to - see for instance Glick (2011), or Cath (2015) (we thank Josh HabgoodCoote for raising this concern). These other weaker versions of intellectualism are not the target of our argument here, since they may hold that the kind of knowledge-that which matters in this respect is special in this particular feature. Nevertheless, even if those views would be unscathed by our argument, they would have to give additional reasons in order to show that the move is not ad hoc, which we think it is. And, furthermore, such views would have to offer an alternative explanation of the way know-how is actually defeated when it is, if not by the traditional ways know-that may be defeated. In so far as such proposals have not been complemented by such explanations, they are in an unfavourable position with respect to anti-intellectualism, which does have such an account- the one we propose in $\S 4$.

13 See however Poston (2009), Cath (2011) and Carter and Pritchard (2015a) for arguments according to which knowledge-how is more resilient to being undermined by epistemic luck than knowledge that. Likewise, see Poston (Forthcoming) for a different argument against intellectualism on the basis of a difference in epistemic properties between knowledge-how and knowledge-that. As Poston argues, knowledge-how cannot be transferrable via testimony in the same manner as knowledge-that. 
lights - a problem if knowledge-how and knowledge-that differ in the way that they are subject to mechanisms of epistemic defeat.

By contrast, the situation would be interestingly different for anti-intellectualism, according to which knowledge-how is grounded not in one's propositional attitudes but rather in one's ability possession. If knowledge-how is not of a propositional kind, then we may expect it to behave differently in the face of propositional states that threaten to rebut or undercut it. Furthermore, given that even within an anti-intellectualist framework, we may expect knowledge-how to be defeasible in some sense, the anti-intellectualist would be in need of some alternative account of what defeaters are for that sui generis kind of epistemic status.

The goal of the rest of this paper is twofold: first, against intellectualism, we will show that knowledge-how behaves differently with respect to traditional propositional defeaters - which is a motive to believe that such an account is misguided. And second, we aim to fill an important lacuna in the contemporary debate, which is to point out an alternative way in which epistemic defeat for knowledge-how could be modelled within an anti-intellectualist framework. In between, we will offer an explanation for the appeal the intellectualist account may have had, which in our view is due to the fact that it partially mirrors genuine know-how epistemic defeat.

The next section is devoted to the first of these objectives-viz., to show that a strictly propositional account of epistemic defeat, i.e., where defeaters are understood as beliefs that one has (in the psychological case) or that one should have (in the normative case) are unable to account for the way know-how may be defeated. In short, knowledge-how appears to be immune to the kinds of defeaters which are capable of defeating the items of knowledge-that which intellectualists identify with knowledge-how.

\section{Intellectualism and Epistemic Defeat: Some Counterexamples}

Consider the following case.

GRENADE FACTORY: Ana and María work in a grenade factory during the Spanish Civil War. They are thoroughly instructed when hired, with examples and practical explanations. By controlled trial and error, they learn their job, and both continue working at the factory for years, believing they are making working grenades. However, one day each comes to realize that the other is making grenades in an importantly different way, and they identify the origin of the problem: as it turns out, the instructions were ambiguous and allowed for two different interpretations. The instructors were not aware of this, and there is nobody above them now who may say who is right. Given that the grenades may only be used in battle, which is very far away, neither Ana nor María knows whose grenades actually work, and so there is no way to find out who is making them the right way. As a matter of fact, Ana got the instructions right (she produces grenades in way $w$, which is the correct way); she is very successful in producing grenades that later work perfectly. It is María who got something wrong (she makes them in $w^{\prime}$, the possible interpretation of the instructions that the instructors did not foresee), and her grenades are always duds. Unaware of this, both have reasonable doubts they did not have before, but they have to keep on working.

Our intuition is that, in GRENADE FACTORY, we may still say that Ana knows how to make grenades, whereas María does not. ${ }^{14}$ However, once acquainted with the fact that María,

14 See here also Cath's (2011), whose inclination is to attribute know-how in a similar kind of case which he terms dogmatic hallucinator. We are grateful to a referee at Philosophy and Phenomenological Research for drawing our attention to this case. 
whom Ana regards as a grenade-making peer, learnt to do them in an importantly different way, Ana does not know anymore that $w$ is the right way for her to make the grenades. Ana, by realizing that María learnt to produce the grenades differently than she did, has now a good reason to suspect that one of the two learning processes went wrong. That furnishes her with a reasonable doubt that $w$, the way she actually learnt, is a way for her to make grenades. Those new doubts then defeat her (would-be) knowledge that $w$ is a way for her to make grenades. Now, though Ana does not know anymore that $w$ is the right way for her to make grenades, still, her grenades are as functional as they have always been, which is a good reason to claim that she continues to know how to make grenades (even if she does not know anymore that she knows how to make them).

As we've detailed the case, GRENADE FACTORY features a defeater that is psychological in character. Ana's knowledge that way $w$ is the way for her to make grenades is defeated by her acquiring the particular belief that she does-viz., that María is making them a different way - a belief which calls into doubt for her the reliability of her own method of making grenades. Granted, Ana, in light of acquiring this belief, might well have lost confidence that she is making the grenades the right way. Her self-esteem may suffer. However, lack of self-esteem and lack of confidence are perfectly compatible with knowing how to do the thing in question. ${ }^{15}$ Provided Ana's doubts do not affect her abilities (and we will say more on this possibility in the next section), the acquisition of a psychological defeater for her (would-be) knowledge that $w$ is the way for her to make grenades is simply not the kind of fact that undermines her know-how.

One natural objection to the GRENADE FACTORY case, as we've described it, is that it trades on a contested premise, namely, what is called in the peer disagreement literature the conciliatory view (e.g., Elga 2007; Feldman 2007). According to the conciliatory view, the rational response to discovering that an epistemic peer disagrees with you about $p$ is to withhold judgment - or, at least, lower your credence - with respect to $p$. By contrast, the steadfast view (e.g., Kelly 2005; 2010; van Inwagen 1996) permits one to rationally maintain one's belief in the face of a discovered epistemic peer disagreement. It might seem superficially that in GRENADE FACTORY, Ana acquires a defeater only if the conciliatory view is correct, though not if the steadfast view is correct. After all, the steadfast view permits Ana to rationally continue believing that $w$ is the way to make grenades, even after discovering that María (whom she regards as a peer) makes them differently.

This objection, however, is misplaced. GRENADE FACTORY is proposed as a case of psychological defeat, and psychological defeaters defeat knowledge simply in virtue of being had. Even if the conciliatory view is false, and rationality doesn't require that Ana withhold judgment (or lower her credence) that $w$ is the way for her to make grenades, so long as she in fact does withhold her judgment—viz., as is described in the case - this suffices for her to acquire a psychological defeater. In short, psychological defeaters don't defeat in virtue of their being rational, per se, but rather, in virtue of being believed and counting, from the perspective of the agent, against the target belief. ${ }^{16}$

\footnotetext{
15 For example, Olympic ski jumpers who perform flawlessly under pressure and who know how to do some of the most difficult jumps, can often experience self-doubt and a loss of confidence in their abilities prior to competition; this is a normal aspect of human anxiety which needn't impair performance. 
We want to now show how a similar point can be made-viz., that epistemic defeaters which defeat the kind of propositional knowledge intellectualists identify with knowledge how, are nonetheless compatible with knowledge how-unequivocally in terms of normative defeat. In order to bring this point out effectively, let's run a slight variation on the original GRENADE FACTORY case.

GRENADE FACTORY*: Holding fixed the details of the original GRENADE FACTORY case, we add a third character, Juana, who has been working in the factory much longer than Ana and María, and so they both regard Juana as more skilled expert than they at making grenades. Juana, Ana and María have all received the same training, but one day they realize that the instructions were ambiguous, and the instructors were not aware of this. As a matter of fact, Ana got the instructions right (she produces grenades in way $w$, which is the correct way), and she is very successful in producing grenades that later work perfectly. But María as well as Juana got something wrong (they make them in way $w^{\prime}$ ), and so their grenades are always duds. Given that the grenades may only be used in battle, which is very far away, and none of the three are told if their grenades actually work or not, there is no way for them to find out which of them interpreted the instructions correctly. Ana comes to realize that, of the three workers, only she is making grenades in way $w$; but Ana is very stubborn, and that she continues to be convinced that her way is the right one, dismissing the fact that both María, whom she regards as a peer, and Juana, whom she regards as a superior, learnt to make them a different way.

There are two key points to glean from this case. Firstly, in the situation so described, Ana should not continue to believe that $w$ is the way for her to make grenades. ${ }^{17}$ Doing so, under the circumstances, would be epistemically irresponsible, irrational, etc. Ana thus has a textbook normative defeater for her belief that $w$ is a way for her to make grenades. Accordingly, Ana does not know that $w$ is a way for her to make grenades. However-and this is the second key point—while neither María nor Juana knows how to make grenades, Ana does.

In both versions of the case we've run, the defeaters acquired are undercutting in the sense that they count against Anna's having correctly learned how to make the grenades, but not directly against whether the grenades in fact operate. ${ }^{18}$ The moral in this respect is that undercutting defeaters, as we've suggested, appeared entirely compatible with knowledge-how even though they undermine Ana's knowledge that $w$ is the way for her to make grenades.

We can make a similar point vis-à-vis rebutting defeat, by simply introducing something which goes wrong in the feedback process rather than-as in the versions of the case considered-the learning process. For instance:

GRENADE FACTORY**: All the women in the factory learnt correctly to produce grenades in the right way, $w$, and have been producing them for some time. One day, they hear over a very reliable civilian radio that the regiment to which their grenades were shipped was soundly defeated due to equipment difficulties involving dud grenades. The information spreads among the women in the factory, and they are no longer confident that $w$ is a way for them to make grenades. Nevertheless, unbeknownst to them, the grenades 
they produce are perfectly functional and the duds ones were produced in a different factory.

If the factory workers believed the report, they would acquire a psychological rebutting defeater for their (would-be) knowledge that $w$ is the way for them to make grenades. If they didn't believe the report, then so long as they would have a good reason to believe that the defective grenades come from their factory, still they should believe it, and accordingly doubt that they are producing the grenades in the right way. They would thus acquire a normative rebutting defeater for their (would-be) knowledge that theirs is the way to make grenades. Still, both psychological and normative rebutting defeaters can be defeated, as could be the case in GRENADE FACTORY**. After all, unaware to them, theirs really is the right way for them to make the grenades, and those that are defective come from another factory. This new information, should they acquire it (for example, from a further update over the reliable civilian radio), could defeat the previous defeater, and restore the piece of knowledge that they are making the grenades in the right way. Nevertheless, the presence or absence of this defeaterdefeater does not affect their know-how, which was simply preserved, unaffected, even while they had reasons to doubt that their way was the right way to produce the grenades.

This puts reductive intellectualism in a bad position, indeed. If know-how really were a case of know-that, we should expect it to be defeasible by the same kinds of mechanisms by which propositional knowledge is defeated. But it is not. In other words: garden variety defeaters of knowledge-that do defeat the knowledge agents have about the ways in which they do what they do. When affected by those defeaters, agents do not know anymore that theirs is the right way to do the activity in question-and, nevertheless, their knowledge-how remains undefeated. That is the case of Ana in each of the variations of our GRENADE FACTORY case: in each of those situations Ana still knows how to make grenades, even if her knowledge-that about her way of doing them is defeated by different mechanisms.

The claim that Ana preserves her know-how along all the variations of the case is supported by the fact that she is still able to make grenades proficiently, and the doubts she acquires do not seem to imperil this ability in any relevant sense. ${ }^{19}$ That affords us a good reason to think that the Rylean account of know-how is in the right track. However, we do not want to deny that there is something closely related to that know-how state that Ana actually lose, and which has some importance: she does not know anymore that she knows how to make grenades.

The way we see it, Stanley \& Williamson's position would be more promising if it had a different cognitive phenomenon as its explanandum-viz., the kind of knowledgethat which we may have about our own know-how-viz., a peculiar kind of propositional knowledge an agent may have about which is a right way for her to $\varphi$, a way of doing that is grasped under a practical mode of presentation. That state is a peculiar kind

19 The success that she still attains when trying to perform her task intentionally is what supports, we hold, her know-how, because that is what her know-how consists in, namely, the ability to accomplish her task in a valuable way, which is something she retains despite the unfavourable circumstances. 
of de se knowledge that we would rather call meta-knowledge about know-how, which ought not be confused with the know-how itself. ${ }^{20}$

In sum, Stanley \& Williamson's proposal may help us understand the peculiar nature of the sort of knowledge-that which we may have about our own knowledge-how-but it is not well aimed in order to uncover the nature of knowledge-how itself. The important point then in favour of our proposal is that the intellectualist alternative fails to account for the cases discussed in this section. That is: there may be know-how even if the agent has no meta-knowledge about it, which is what our variations of GRENADE FACTORY cases show. ${ }^{21}$ That knowledge-how would then be an epistemic state that, not being propositional, would be immune to propositional defeat.

Nevertheless, it remains to be seen whether genuine know-how may be susceptible to being defeated by other sort of mechanisms. We hold that it certainly is, and the rest of the paper is devoted to showing how this is possible. Our claim in this respect is that know-how is genuinely defeated at least in some situations where the related ability is undermined in certain (to-be-specified) particular ways. If our view is correct, anti-intellectualism may be in a better position to account for how knowledge how is actually defeated, when it is.

\section{Modelling Epistemic Defeat for Anti-Intellectualism}

In this section our goal is to show that an anti-intellectualist account of knowledge-how can succeed where the intellectualist account fails. And we will pursue this goal by proposing a novel way to model defeaters for knowledge-how within an anti-intellectualist framework. As an initial step, though, we want to note two desiderata that such an account will need to satisfy. First, in light of the conclusions drawn in $\$ 2$, such a model will have to be constructed along different lines than those followed by the traditional model of epistemic defeat, according to which the relata in epistemic defeat relations are fundamentally propositional attitudes. In particular, defeat relations for knowledge-how must not be modelled as relations whereby what is defeated is a justified belief, and what does the defeating is a proposition which is, or should be, believed.

This leads to a second, more specific desideratum. Consider that, on the standard model of epistemic defeaters for knowledge-that (according to $\$ 1$ ), defeaters call into doubt the status of believed propositions by undercutting their putative justification or by

20 If an agent has this sui generis kind of propositional knowledge, then, trivially, she has the ability in question in the sense we give to the term (that is: she would be able to $\varphi$ in way $w$ if she tried in the relevant circumstances). In other words: Stanley \& Williamson's knowledge about ways would trivially implicate know-how, because, if one has such a state, one knows that one knows how to $\varphi$, and thus one knows-how to $\varphi$. Just as any other kind of propositional knowledge, Stanley \& Williamson's knowledge about ways is factive, and implicates the truth of what is known-viz., if it is meta-knowledge, it implicates that one knows how to $\varphi$. Glick has already made the claim that Stanley and Williamson's knowledge about ways may be read as knowledge the agent has of her own abilities: "according to the standard views in linguistics to which Stanley and Williamson appeal, 'S knows how to $\varphi$ ' has an interpretation on which it means that $\mathrm{S}$ knows something like that he can $\varphi$ in way $w$, and hence entails that $\mathrm{S}$ can $\varphi$ in way $w$, and hence entails that $\mathrm{S}$ can $\varphi$ " $(2012,137)$. The suggestion we are making here is stronger, in the sense that it would not only be the ability, but the know-how itself, what would be the object of this kind of de se knowledge.

21 Interestingly enough, the lack of meta-knowledge seems to be more permissible in the case of know-how than in the case of knowledge-that. That is: nothing seems to be wrong intuitively in an agent knowing how to $\varphi$ but not knowing that she knows how to $\varphi$, whereas it seems at least disputable that an agent may know that $p$ but not know that she knows it (see, for instance, D. Greco, 2014). 
rebutting their putative truth. Put more abstractly: epistemic defeaters either target the warrant of the belief (its justification) or its success component (its truth). ${ }^{22}$ Accordingly, on a viable anti-intellectualist account of epistemic defeat for know-how, epistemic defeaters must target either the warrant status, or the success component, of something else.

In other words, in order to satisfy our first desideratum, we have to find an alternative for belief as the state that is defeated, whereas in order to satisfy our second desideratum, we'll need to posit different properties of that state as the ones that are defeated, in such a way that it would allow the anti-intellectualist to formulate distinctions potentially equivalent to the undercutting/rebutting one.

Accordingly, in order to satisfy the first desideratum, what our proposal submits (roughly for now, and in a way we will continue to refine) is that it is abilities themselves which are undermined when knowledge-how is defeated, rather than beliefs about those abilities, beliefs about ways for one to do something, or beliefs about anything else. In short: what we want to suggest is that it is not a propositional state of the agent, but the ability itself, the power, the capacity, that is compromised when her knowledge-how is defeated.

But what does it mean to say that an ability may be defeated, and by what mechanisms is that possible? Here it will be helpful to reflect on some different ways in which one is no longer able to do something one was once able to do. To this end, consider the following two variations on a case: ${ }^{23}$

CHEF-A: A highly skilled chef becomes afflicted with arthritis, after which she can no longer prepare her signature dish of Anginares a la Polita.

CHEF-B: A highly skilled chef becomes afflicted with Alzheimer's disease, after which she can no longer prepare her signature dish of Anginares a la Polita.

On an initial first pass, it might seem as though we should regard both situations as cases where the relevant ability (i.e., the ability to make the Anginares a la Polita) is undermined and therefore, as cases that equally demonstrate abilities to be defeated. And so, initially, it might seem as though the answer to the question: 'How can abilities be defeated?', would be: through disabling conditions, such as arthritis or Alzheimer's.

While this answer is somewhat on the right track, we think it's too quick, and that it glosses over an important distinction. Consider, for one thing, that there is something further that the chef loses in the case of CHEF-B, which is not lost in the case of CHEF-A, and correspondingly, something valuable that the chef retains in CHEF-A but not in CHEF-B. And this is so even though neither chef can make the signature dish anymore.

In CHEF-A, the chef, via the arthritis, clearly loses the opportunity to manifest her ability, much in the way a pianist who is imprisoned (or, who happens to be underwater) loses the opportunity to manifest her ability. The new impediment, in this case, affects the agent's physiological status, it is true, and it does so in such a way that it could even be irretrievable. But (to put it simply) all is not lost. The chef in the first case is surely

22 According to normativists about belief (e.g., Engel 2004; Shah \& Velleman 2007, Shah 2005, Wedgwood 2002), that truth is the epistemic standard of correctness for belief is constitutive of belief-viz., it is part of what it is to be a belief (as opposed to some other attitude) to have such standard. Though, one needn't embrace normativism about belief in order to embrace the weaker platitude that beliefs are correct if and only if true; or, in slogan form, that beliefs aim at truth. 
not in the same position as a complete amateur. Put her in the right circumstance-viz., where the arthritis subsides - and she can then prepare her signature dish in a way that manifests her ability.

In CHEF-B, however, things are considerably worse. It seems plausible to regard the chef, suffering Alzheimer's disease, as lacking not merely opportunity to exercise her ability, but the ability itself. ${ }^{24}$ (Consider: the chef in CHEF-A doesn't need to re-learn to do anything; just let the arthritis pain subside; the chef in CHEF-B, however, even if she were cured from her disease, would be no better off than a beginner. In CHEF-B, in order to make Anginares a la Polita, the chef with Alzheimer's disease would need to re-learn all the steps, and unfortunately in some cases this is simply impossible.)

A lesson to draw from this comparison is that making inaccessible the opportunity conditions for manifesting an ability needn't itself defeat the ability in question. Rather, an ability should be regarded as defeated only if, if the opportunity were suitably present, the agent would systematically fail—viz., even if she were in the right opportunity conditions to $\varphi$, she would not be able anymore to $\varphi$ if she tried.

Before moving on, let's briefly take stock. To this point, we've suggested that, on any viable anti-intellectualist account of the defeasibility of knowledge-how, abilities themselves (and not propositional attitudes) must stand in defeat relations, and further-with reference to the above comparison of cases - we've distinguished between defeating an ability simpliciter (as in the case of CHEF-B), and (more weakly) merely preventing an ability from being manifested (as in the case of CHEF-A), where the latter falls short of genuinely defeating the ability. ${ }^{25}$ The moral here was that what matters of the attribution of an ability is the agent's capacities to manifest it in the relevant circumstances. ${ }^{26}$ Not all cases of disability are then knowledge-undermining but, perhaps, only those that prevent the agent from manifesting the ability in some opportunity circumstances that should be, in principle, appropriate for that manifestation. ${ }^{27}$

24 About the distinction between opportunity "can" and ability "can" see Austin (1961, 177), which Glick $(2012,131)$ has also applied to the debate on knowledge-how.

25 Intellectualists have claimed that, when the opportunities to exercise the ability are modally far away (as in CHEF-A, or in the much discussed case of a pianist who loses both hands in a tragic accident), the agents actually lose their abilities, given that they will most probably never be able to manifest them again (Stanley and Williamson 2001, 416; Stanley 2011, 128). We find this misleading, though. We could imagine, for instance, a situation where not only all pianos in the world would be destroyed, but also all piano builders together with all the knowledge of how to build a piano. Just like the unfortunate pianist would be modally far away from the possibility of playing the piano after losing her hands, so would be any pianist in this imagined world where no more pianos will ever be available again. Nevertheless, we hold that both sorts of pianists would still keep their abilities in the relevant sense-viz., they would both still be able to manifest their abilities if the conditions were recovered (no matter how modally far away that possibility is). Our point is that this modal distance with respect to opportunity 'can' is of a different nature than the impossibility manifested in the Alzheimer's case. If we could envisage new manifestation opportunities for our chef in CHEF-B, they would certainly involve a completely new learning process for her, which means that the innermost ability itself would have been lost and ought to be recovered - and so would be, we claim, her know-how.

26 For related discussion on this general point, see Sosa $(2010,466)$.

27 Having arthritis, having one's hand's amputated, being incarcerated, or being under water, are not circumstances where agents are expected to be able to manifest their abilities. Therefore, the fact that agents find themselves in those unfortunate circumstances-no matter how difficult or even impossible it is for them to get out of them - should not be considered as a disabling condition, in the sense that interests us. On the contrary, what really matters is the agent's capacity to succeed in the right circumstances-a point that, as Hawley (2003) has insightfully shown, should be considered as a common ground for all contenders in this debate. 
What counts as the 'right circumstances' is a complex issue. ${ }^{28}$ By the same token, (as we'll see) the sort of disabling conditions that are of interest for us, in so far as they function as knowledge defeaters, may affect an agent in very different ways. In order to sharpen these points, it will be helpful to review Ernest Sosa's (e.g., 2015) 'triple S' analysis of competences: ${ }^{29}$

Competences are a special case of dispositions, that in which the host is disposed to succeed when she tries, or that in which the host seats a relevant skill, and is in the proper shape and situation, such that she tries in close enough worlds, and in the close enough worlds where she tries, she reliably enough succeeds. But this must be so in the right way $(2015,23)$.

There is no doubt that pianists with no piano available, chefs fresh out of ingredients, and golfers in Antarctica are not in the proper situation to manifest their abilities, but those who are amputated or have arthritis cannot manifest them because they are not - in Sosa's parlance - in proper shape. Nevertheless, it may be argued that all of them preserve the relevant skill provided it's true that, if they were in proper shape and the right situation, they would be able to manifest that skill reliably enough, something that would not be true of unfortunate CHEF-B, who would have lost even the seat of her skill. As Sosa (2015) puts it:

Drop the situation and you still have an inner SS competence. Drop both shape and situation and you still have an innermost $\mathrm{S}$ competence: that is, the basic driving skill retained even when asleep (in unfortunate shape) in bed (in an inappropriate situation) $(2015,26)$.

The limits between skill, shape and situation are anything but clear, and philosophers of mind and cognitive science working on situated cognition might have valuable input here. ${ }^{30}$ Perhaps the skill is extended to the limbs of the agent (embodiment), ${ }^{31}$ or perhaps some aspects of the situation are part of the agent's cognitive system (extended cognition), ${ }^{32}$ but in any case, the following is clear enough: attributions of abilities or competences are always made with the idea of right circumstances of manifestation in mind, where SSS conditions are met.

Let's now refine things further in order to meet our second desideratum, which was to find (roughly) analogous features to justification and truth that can feature as aspects of the ability that are defeated in cases of know-how. Recall that, on the propositional model canvassed in $\S 1$, knowledge-that could be defeated in either an undercutting or rebutting manner, depending on whether it is the justification of the belief or its truth that the defeater calls into doubt. It verges on a category mistake to talk about the justification' of an ability, which is not a propositional state, and much less about its 'truth',

For a recent discussion of this point, as concerns the exercise of cognitive abilities in (propositional) knowledge acquisition, see Greco (2012).

29 A similar application of Sosa's distinction may be found in Tsai (2011) and Kotzee (2016).

30 See, for example, Wilson and Foglia (2016) for an overview.

31 See Noë (2005) for similar claims.

32 For the classic defence of this view, see Clark and Chalmers (1998). Cf., Carter and Czarnecki (2015) for a limited defence of extended abilities, as relevant to knowledge-how on an anti-intellectualist construal. 
since abilities are not representational states with propositional contents. In this respect, a natural question becomes: is there some feature (or features) of abilities that may help support a distinction analogous to undercutting versus rebutting modes of defeat in an anti-intellectualist epistemology of knowledge-how?

It seems as though the answer could be 'yes' provided there are also relevantly different fashions in which one's abilities could be defeated. To a first approximation, this will be by the imperilling of each one of the aspects of the standard conditions where the agent is expected to manifest the ability, that is, each of its SSS components. In other words: the ability to $\varphi$ is genuinely defeated only when, even if the agent were in the relevant situation, in the right shape, and in her own seat, she would be not able anymore to $\varphi$ reliably enough if she tried.

Against this background, and with Sosa's categories in mind, we are in a position now to offer some illustrative cases of the types of disability that produce epistemic defeat. These cases will be-like the ones where propositional knowledge is defeatedsituations where an agent has some epistemic state (viz., knowledge) that is downgraded up to the point that it no longer qualifies as knowledge. In other words: we are targeting situations where an agent that previously knew how to $\varphi$ is such that she does not know anymore how to $\varphi$.

These situations arise, we hold, as an effect of some mismatch between the agent's powers and the relevant SSS conditions where those powers are expected to be manifested. And we submit that such a mismatch may be produced in at least three different ways.

(i) First, it could be that the agent is not able anymore to $\varphi$ in a given situation (or range of situations) that is, or has become, the relevant one for her to $\varphi$.

(ii) Second, it could be that the agent is not able anymore to $\varphi$ in a given shape that is, or has become, the relevant one for her to $\varphi$.

(iii) Third, it could be that, even if we hold fixed that the situation and the shape she is in are the same as when the agent was able to $\varphi$, she can no longer $\varphi$ because she has lost the very seat of her skill.

We will discuss these three possibilities in what follows.

\subsection{Situational defeaters}

An agent's knowledge-how is defeated by a situational defeater when the agent previously knew how to $\varphi$, but she does not know anymore due to a change in the situation that is relevant to the assessment of her abilities. Note that the situational defeat of one's knowledge-how is compatible with the agent retaining her ability to perform in some previous circumstances, those that supported the original know-how attribution. It is just that those circumstances are no longer relevant to whether she counts as knowing how to do the activity in question.

Consider the following case:

OBSOLETE BROKER: Laura has been an excellent stock broker for twenty years, during the '70s and '80s. She helped her clients earn a lot of money in those years, as did she herself. Unfortunately for Laura, the rise of new technologies has caused the job to become 
very different from what it was. Everything relies now on complex computerized systems that Laura is unable to master. Overwhelmed by the mechanisms of high-tech trading, she finds herself unable to competently assess financial risk. Progressively, Laura's once satisfied clients abandon her, complaining that she does not know anymore how to make money for them.

In this case, the natural description of the scene is one in which Laura used to know-how to make money in the stock market, but doesn't anymore. We grant that if the know-obsolete technology of the '70s and ' 80 s, which can no longer be used to effectively manage financial risk assessment, was currently relevant to making money in the stock market, then Laura would still know how to make money in the stock market. But it's not, and so she doesn't. An unfortunate change in the situation defeats her knowledge, and her state is downgraded in epistemic status. OBSOLETE BROKER features then a case of what we will call a situational stative defeater, in accordance with an anti-intellectualist understanding of know-how. It is anti-intellectualist because it is the agent's new lack of ability is what explains the defeat of her knowledge, rather than the acquisition of some new propositional state related to her justification. It is stative (in contrast to normative) because the relevant situation changes as a matter of fact, and not because of a change in the normative regulation. And it is situational because the new conditions affect the external aspect of the SSS conditions where the agent would be expected to succeed if she knew how.

Consider now a similar case where defeat is due to changes in the normative context:

OBSOLETE GYMNAST: Ebba is a very successful gymnast who has won several Olympic medals on the vaulting table. In particular, her speciality is the extremely complex and demanding stunt $\mathrm{E}$, which she has mastered to perfection. One day, the Olympic committee issued a surprise announcement. Due to evidence that certain aspects of gymnasts technique on the vaulting table have been linked to spinal cord trauma, these aspects have now been banned in competition. They were, however, crucial in Ebba's exceptional performance of E. With the new rules in play, Ebba is significantly limited in what she can accomplish on the vaulting table, and in particular, she does not know anymore how to finish stunt $\mathrm{E}$ correctly (i.e., in accordance with the rules).

In OBSOLETE GYMNAST, what changes are the normative standards for success, which define a canon for the activity in question, establishing its model of correctness. If it is the ability itself that is so defined, then (for example) Ebba's new situation in OBSOLETE GYMNAST should be described as one where she no longer has the ability to do perform jump E. And, as an effect of this failure in her ability, it is no longer the case that she knows how to do jump E.

We hold that this case thus features a normative situational defeater for knowledge-how, conceived along anti-intellectualist lines. It is normative because, in light of the change in the constitutive norms that govern what counts as a valid way of E-ing, Ebba should not perform the act anymore the way she used to-in the sense of 'should' that features in the claim that the chess player should not move her knight three spaces forward. ${ }^{33}$ Note that

33

Our case of Ebba is one where - according to Searle's distinction (1969) - the activity is not merely regulated by norms, but even more, the norms are constitutive of the activity itself. A question may be raised as to whether normative situational defeaters might also feature in cases where the normative standards that shift are regulative, rather than constitutive, of the activity in question. We believe that they do. For instance: a change in regulative norms concerning fishing, which most authors consider as an activity regulated by rules but not constituted by them, may have the effect that some agent in particular does not know anymore how to fish according to the new normative context. 
even if Ebba were stubborn and proceeded in her familiar method, her performance would not count as stunt E anymore, and she would thus not succeed in her attempt to do it. (Continuing the chess analogy: if one does not move in accordance with the rules of castling, one has not castled, but has rather done something else, or nothing valid at all). Finally, the normative situational defeater described is thoroughly anti-intellectualist because what actually produces the defeat is not some change in Ebba's propositional attitudes. Rather, what produces the defeat in this case is a change in the standards that define the ability itself.

It will be helpful here to quickly raise and reply to two anticipated objections. The first of them proceeds as follows: our diagnosis of Ebba's situation conflates distinct abilities in the service of illustrating what we're calling a normative situation defeater. Call $E_{1}$ the ability Ebba had mastered before the new regulations, and $E_{2}$ the ability she is required to perform once the regulations change. $E_{1}$ and $E_{2}$ are simply not, according to this objection, the same ability, and thus, Ebba's knowledge-how was not, as we are suggesting, defeated, but rather, a different kind of know-how is now required from her: one that she does not have, but of whose ignorance is compatible with the know-how she still retains-viz., to perform the $\mathrm{E}_{1}$ stunt. Or so this objection goes.

We think such an interpretation should be resisted. On closer inspection, the objection has considerable baggage: a revisionary way of thinking about abilities that conflicts with our ordinary attribution patterns. It is hard to deny that, both when the relevant facts about the situation change, or when the standards for regulated activities change, we very naturally deny knowledge-how to agents who are unable to act according to the new conditions and/or regulations, and we do not insist that agents still do know-how to perform them. Unless the agent is actually able to perform in accordance to the new conditions or rules, the inclination is to say that she does not know how to do it anymore. To the extent that this is right, the observation that E1 and E2 can be conceived of as distinct abilities - something we do not deny-doesn't go very far toward undermining the thought that Laura or Ebba used to know how to succeed in the previous conditions, but now do not know anymore.

The second objection would consist in claiming that what Laura and Ebba lack is similar to what our CHEF-A lacked, i.e. the mere opportunity to manifest their abilities, and not the abilities themselves. If that alternative diagnosis were right, our cases would not be featuring situations of genuine epistemic defeat, for the very same reasons that we had claimed that CHEF-A did not feature a genuine case of epistemic defeat-i.e. new conditions do not undermine the ability itself, but consist in a mere lack of opportunity to manifest it. However, we also have a principled reply to this objection. In our view, there is some feature common to Laura's and Ebba's new context that is lacking from CHEF-A's one, namely: CHEF-A may not be properly required to perform in his new conditions, and shall not be sensibly expected to do so. It would be unfair to ask chefs in general to perform the physical activities required by cooking when affected by severe arthritis. Nevertheless, the factual or normative changes affecting Laura and Ebba are such that they are both fairly required to, and expected to, succeed in these new conditions, if they want to preserve their status of knowledgable agents. Unless they had the ability to succeed in their respective new conditions, we would not be allowed to claim anymore that they know how to do it. In contrast to CHEF-A, OBSOLETE BROKER and OBSOLETE GYMNAST are 
situations where the opportunity for manifesting the ability is not simply lacking: the relevant opportunity is there, it is just that those agents are not up to it anymore. ${ }^{34}$

Two final points about our cases of situational defeaters are relevant to note. Firstly, what is imperilled in both cases is the ability itself, viz., the ability to succeed under relevant circumstances. In both OBSOLETE GYMNAST as well as OBSOLETE BROKER, nothing internal to the agent changes - that is that is perhaps the problem!- but their capacities become ineffective, and they lose their powers rather than — as per intellectualism-losing epistemic status vis-à-vis some representational attitude(s).

Secondly note that even if our two cases share the idea that the change is in the relevant external context, that is, in the situation, they are different in an interesting respect: the way the case is described, Laura's problem is not normative in the sense that Ebba's is. What's problematic for Laura is (in short) the way things are, or the way they are not anymore. However, Ebba's situation in OBSOLETE GYMNAST has to do with how the task is defined according to some normative standards. It has to do with changes in what she should or shouldn't do, in what is allowed or forbidden, in order to that performance to count as acceptable, or valuable. For that reason, we hold that situational defeaters for know-how may be stative or normative, depending on whether what changes in the situation is the way things actually are, or the normative context the action ought to conform to.

\subsection{Shape defeaters}

An agent's knowledge-how is defeated by a shape defeater when the agent previously knew how to $\varphi$, but the agent does not know anymore due to a change in the agent's shape that is relevant to the assessment of her abilities. In such cases, the crux of the problem is a mismatch between the agent's capacities to perform and the relevant shape in which she is expected to succeed-viz., that she is no longer able to successfully $\varphi$ in a shape in which she is now expected to do. Note that, just as with situational defeaters, the defeat of one's knowledge-how via a shape defeater is compatible with the agent retaining her ability to perform in some previous shape(s), those that supported the original know-how attribution. It is just that such shape(s) are no longer relevant to whether she counts as knowing how to do the activity in question, because she is now unable to do it in a shape that has become central for the new SSS conditions.

As we did for situational defeaters in $\$ 4.1$, we will introduce two cases that respectively feature stative and normative shape defeaters:

WRECKED GYMNAST: Viggo is a very promising gymnast, who has always idolised the legendary Viktor, the most famous gymnast in their country's history. Viktor learned about Viggo's exceptional potential from their common trainer, and became jealous. After watching Viggo perform stunt V, Viktor makes a devastating-though completely unfair — criticism of Viggo's performance. Seriously affected by his idol's verdict, Viggo becomes very nervous whenever he thinks that Victor is watching him, which he expects

In contrast to our two obsolete cases, we could imagine others that would be relevantly similar to CHEF-A, and thus feature cases of lack opportunity. For instance: our broker could have lost her client's confidence due to some affair not related to her competence in such a way that nobody would ask her anymore for her services. Or the whole national delegation the gymnast belongs to could have been banned from competition. These would be properly considered as lacks of opportunity, but not as cases of epistemic defeat. Stokes brokers may not be asked to perform their job deprived of all sources of funding, and gymnasts are not expected to succeed in competitions where they are not allowed to participate. 
to happen just in any important competition. If he suspects Victor is watching him when he is about to perform stunt $\mathrm{V}$, he confuses, and can't remember, the steps required to execute the stung; consequently, he miserably fails, or (at least) performs very poorly.

DOPED CHESS PLAYER: Vladimir is an excellent chess player who has always used a certain substance-Adderall - that his trainer recommended before his matches to help control for his ADHD. Adderall helped him concentrate very well, and to master the complex Ruy Lopez opening, including many of the nuanced variations on this opening (his skilful execution of the Ruy Lopez involved anticipating up to 15 to 20 moves ahead). Vladimir, through his use of the Ruy Lopez opening, became a successful tournament player. Once the World Chess Federation came to view Adderall as an unfair form of cognitive enhancement, the substance was prohibited; subsequently, Vladimir (absent the Adderall) is unable to concentrate long enough to execute the Ruy Lopez effectively in competition. In fact, he is convinced that he does not know anymore how to Ruy Lopez, if he is not allowed to have his drug.

As was the case with situational defeaters, our cases of shape defeaters might be contested on the alleged grounds that Viggo and Vladimir still do know how to perform in some set of SSS conditions: their performance has just been compromised when they are in some particular shape.

However, our reply to this suggestion is consonant with our reply to the analogous form of objection canvassed in $\$ 4.1$. In short, the shapes in which they are not able to perform anymore are the relevant ones, whereas the shapes in which they are still able to perform are not. As an effect of his new psychological shape, Viggo cannot perform well anymore in any important competition - given that the thought that Viktor is observing makes him too nervous - and Vladimir can only manage the focus required to successfully execute the Ruy Lopez if he is in a state - under the effect of a Adderall - that is now prohibited in competition. Therefore, in so far as Viggo and Vladimir would succeed, respectively only in shapes that have become irrelevant, they do not know anymore how to perform.

In the WRECKED GYMNAST case, the problem is a positive (stative) change in the sense that what has changed has nothing to do with regulations and norms, but just with the state the agent is now, as a matter of fact. However, in DOPED CHESS PLAYER we find a change in regulations and norms as the debilitating factor that had a deleterious effect on Vladimir's powers. The shape Vladimir would be able to succeed has simply become irrelevant, due to the fact that being in that shape is forbidden.

\subsection{Seat defeaters}

An agent's knowledge-how is defeated by a seat defeater when the agent previously knew how to $\varphi$, but she does not know anymore due to a change in the agent's seat that is relevant to the assessment of her ability to $\varphi$. In such cases, even if we hold fixed that the relevant external situation and the relevant shape she is in are just the same as when the agent was able to $\varphi$, she can no longer $\varphi$ because she has lost the very seat of her skill. Seat defeaters, in short, undermine the innermost seat of the agent's competences.

Consider the following two cases, the first-featuring former New York Yankees second baseman Chuck Knoblauch - is due to Hubert Dreyfus (2007). The second, concerning a rare loss of synaesthesia in an artist due to brain trauma, is taken from a study reported by Sacks et al. (1988).

ABSORBED BASEMAN: [...] Knoblauch was... voted best infielder of the year, but one day, rather than simply fielding a hit and throwing the ball to first base, it seems he stepped 
back and took up a 'free, distanced orientation' towards the ball and how he was throwing it - the mechanics of it, as he put it. After that, he couldn't recover his former absorption and often - though not always - threw the ball to first base erratically — once into the face of a spectator (Dreyfus, 2007, 354).

SYNAESTHESIA ARTIST: A patient, 'Mr. I.' was a successful artist, with a specialty in painting. Mr. I's artistic skills were enhanced through his intense synaesthesia, which allowed him to experience musical notes as colours. At the age of 65 , he was in an automobile accident after which he acquired cerebral achromatopsia, or colour-blindedness, and with the colourblindedness, he lost his synaesthesia and his abilities to paint.

One might initially suggest that ABSORBED BASEMAN and SYNAESTHESIA ARTIST feature what we called shape defeaters in $\S 4.2$, as were illustrated in the cases WRECKED GYMNAST and DOPED CHESS PLAYER. We maintain however that ABSORBED BASEMAN and SYNAESTHESIA ARTIST are importantly different from the cases featuring shape defeaters: in these cases, the problem is not that the agents are in a state that is transitory, a state they may get in or out of. Rather what transpires is a radical change in the way they are.

Consider, briefly, an example Sosa $(2015,96)$ offers in the case of the seat of one's ability to drive a car. This is, as he puts it, the 'innermost' competence-viz., the 'structural seat in one's brain, nervous system, and body, which the driver retains even while asleep or drunk'. The seat, so understood, remains intact throughout changes in shape. The changes to Knoblauch's and Mr. I's mental lives are fundamental ones, not like being asleep, or drunk; what has happened to each is held fixed as the shape each is in can fluctuate.

In the case of SYNAESTHESIA ARTIST, the cause of seat change is an injury-induced pathology, whereas ABSORBED BASEMAN features something that is curiously psychological - viz., what is colloquially termed the 'yips'. The underlying causes of the yips, which have in many cases been career-ending for competitive athletes, ${ }^{35}$ continues to be studied and debated by sports psychologists. ${ }^{36}$

At this point, it will be helpful to take stock of our taxonomy of defeaters for knowhow, with reference to the cases discussed thus far. ${ }^{37}$

\begin{tabular}{|c|c|c|}
\hline & Stative & Normative \\
\hline Situational & OBSOLETE BROKER & OBSOLETE GYMNAST \\
\hline Shape & WRECKED GYMNAST & DOPED CHESS PLAYER \\
\hline Seat & $\begin{array}{c}\text { ABSORBED BASEMAN } \\
\text { ¿ } \\
\text { SYNAESTHESIA ARTIST }\end{array}$ & ${\mathrm{N} / \mathrm{A}^{37}}^{37}$ \\
\hline
\end{tabular}

Note that whereas we have introduced normative (along with stative) defeaters in both $\S 4.1$ and $\$ 4.2$ for situation and shape, respectively, we submit that there is a principled

35 This yips have been career ending for baseball players (along with Knoblauch) such as Steve Sax, Rick Ankiel, Steve Blass and Mickey Sasser.

36 For example, in a study by Stinear et al. (2006), the phenomenon of the yips in golf has been argued to admit of two subtypes, based on symptoms reported. One kind of yips, 'Type 1', involves primarily reported movement-related symptoms, whereas another type (Type 2) involves primarily anxiety-related symptoms. For related discussion, see Papineau (2015). see, however, the FORBIDDEN CYBORG case in fn. 38. 
reason why the seat of a competence is immune to normative defeat. Norms regulate social and public performances, which accounts for why the characters in OBSOLETE GYMNAST and DOPED CHESS PLAYER fail to know how to perform their respective activities in the relevant SSS conditions; what counted as the relevant situation and shape in those respective cases changed due to socially, publically, politically, etc. sanctioned changes. It is unclear to us that such normative changes may forbid the innermost seat of one's competence and still feature as genuine cases of epistemic defeat. ${ }^{38}$

\subsection{Inhabilitating vs. Downgrading Defeat}

Within each of the categories taxonomised in our chart in $\$ 4.3$, we can introduce two modes, corresponding with inhabilitating and downgrading defeat. In the former case, as an effect of the epistemic defeater, the agent simply loses the ability to $\varphi$, whereas in the latter case, the agent is still able to perform the activity in question in the new SSS relevant combination, but not to the same standards of excellence.

In certain simple cases, there is no clear need for such a distinction. For example, there is little room for gradable mastery in opening a door: once one is able to successfully open a door, one will typically thereby know how to open a door as well as anyone, as well as it's possible to know how to do it. But the interesting cases for a promising epistemology of know-how, we think, are those where agents are expected to meet standards that have a certain complexity, and attain some form of success that may be qualified as mastery beyond mere success.

38 If anything like a normative seat defeater for know-how were conceivable, it would have to be a situation where an agent would be unable to $\varphi$ (or to $\varphi$ as well as she used to) due to some normative change that forbids the qualities of her innermost seat: it should not be a normative change that merely affects the situation where the agent used to manifest the ability, nor a change that merely forbids the shape the agent used to be in when performing, but a new norm that actually forbids, in short, who the agent actually is, the permanent and innermost seat of her skill. The closest we can come to imagining such a scenario is the following:

FORBIDDEN CYBORG: Imagine that we live in a society inhabited by both humans and cyborgs, where the latter had been cognitively enhanced via some chips so deeply integrated in the cyborg cognitive architecture that their very existence depends on them. The state of the chips, indispensable to the cyborgs as our (for instance) brain is to us, constitutes part of the seat of their competences to engage in intelligent behaviour, e.g., to play chess, and not merely what shapes they are in. Put another way, these chips, which permit the cyborgs to play remarkably skilled chess, are not analogous to drugs, which engender a transitory state, but to the cyborg's baseline brain state. That said, imagine some change of regulations in that society according to which cyborgs would, in virtue of the chip - discovered to have amazing benefits in chess - no longer allowed to lay in chess tournaments.

In such a case, it would seem as though the cyborg's previous knowledge might be defeated by a normative seat defeater: they would allegedly not know how to play chess anymore because they would be forbidden from exercising their innermost competence to play it. Our intuition, however, is that the right diagnosis of FORBIDDEN CYBORG is as follows: that cyborgs do still know how to play chess, only that they have been banned from being in the right opportunity to manifest that ability. Vladimir's situation is completely different in this respect, since he would be unable to play in the relevant shape, but nonetheless permitted to do so. We may reasonably require Vladimir to play well not being under the effects of the drug, but we may not reasonably require the cyborg to play well while not being a cyborg. Such a requirement is arguably incoherent. In sum, the above putative case of a normative seat defeater would then be better described as a situation where the agent is precluded, for normative reasons, from having the opportunity to manifest her abilities. We remain open though to the possibility that there be other cases we have not been able to imagine that featured that kind of case. 
Consider that there is an important difference between having the ability to play football and knowing how to play it (well), as there is a difference between being able to run a company and knowing how to run it (well), or being able to address a large audience and knowing how to do it (well). In each of these cases, the flat-out attribution of know how points to a more valuable state than just the capacity to attain minimal success. The knowhow is more valuable, but not necessarily different in essence from the capacity. The valuable know-how in such complex cases reflects a certain level of mastery of that capacity.

With these points in mind, it should be clear now why (at least, within the kind of anti-intellectualist programme we're pursuing) defeaters for know-how will not be exclusively inhabilitating; they might also downgrade the agents' knowledge-how to $\varphi$ in a manner such that the ability to achieve minimal success at $\varphi$-ing is preserved, though its exercise is less valuable, less masterful, than before. ${ }^{39}$

That knowledge-how will be defeasible in a downgrading mode, and not only in a inhabilitating one, should be expected; just as the concept of know-how is gradable, ${ }^{40}$ so should we expect that the possible defeasibility conditions of know-how could in some way reflect this. Thus, for the available static and normative varieties of situation, shape and seat defeaters, we may distinguish between inhabilitating and downgrading modes. In other words: each of our agents in those cases may become simply unable to perform at all once the defeater appears, which would make them cases of inhabilitating defeaters; or they may be unable to perform as well as they did before, which explains why they do not know how to do it as well as they did before the appearance of the defeater. In that latter case, the examples would feature situations of downgrading defeaters, which have as an effect a certain loss in the final value of the agent's attainments. ${ }^{41}$

One final point is of relevance here: it is common ground that traditional epistemic defeaters for knowledge-that may themselves be defeated. The acquisition of new information may defeat an agent's rebutting or undercutting defeater, upgrading her cognitive state back to the level of knowledge-that. The same thing may happen, we hold, in the case of epistemic defeaters for knowledge-how, across all the categories proposed. For instance, in OBSOLETE BROKER the arousal of user-friendlier technologies could potentially help Laura deal with the new conditions of the stock market, allowing her to recover her

39 See Carter \& Pritchard (2015c) for discussion of the value of knowledge-how in comparison with the value of knowledge-that.

40 For an excellent discussion of the gradability of know-how, see Pavese, forthcoming.

41 A reviewer at Philosophy and Phenomenological Research has expressed the concern that states such as desires could also be 'defeated' in a sense similar to the one we propose here, however, such defeat would be on closer inspection orthogonal to epistemic defeasibility. For instance: changing facts and norms may debilitate conative states such as desires, perhaps entirely. However, we doubt that such a phenomenon has the characteristics we explore here with respect to knowledge-how. In particular, desires do not seem to have the normative character and value that we confer on knowledge states, and which justifies in our view that epistemic defeasibility for knowledge-how may be stative or normative, as well as inhabilitating or downgrading. We may say, for instance, that an agent does not know how to $\varphi$ after some changes in the norms that constitute or regulate the activity in question, as happens in OBSOLETE BROKER Or OBSOLETE GYMNAST; but a similar normative change would not immediately justify the 'defeat' of a desire, which may be simply preserved (both in its phenomenal character and its motivational strength) in the agent's mind, despite those normative changes. We find this difference important: some object becoming forbidden does not imply that it is not desired, but some way of $\varphi$-ing becoming forbidden may imply that the agent does not know how to $\varphi$ anymore (and is thus inhabilitated), or does not know how to $\varphi$ as well as she used to anymore (and is thus downgraded in her ability). Knowledge-how states are then conferred on-or denied to-agents as a result of a normative and social practice of epistemic evaluation in ways that are structurally very different from desires. 
previous capacities; in OBSOLETE GYMNAST, likewise, a new change in the regulations may allow Ebba to perform stunt $\mathrm{E}$ in a way that manifests excellence; and so on. Given that those new facts or norms have the consequence that agents recover the capacity to perform in the relevant SSS conditions according to their previous standards of excellence, they function as defeaters of the previous defeaters. ${ }^{42}$ Fortunately, not all defeasibility has to be as definitive and irretrievable as the one we encounter in CHEF-B.

\section{Concluding Remarks}

In this paper we have shown, first, that the intellectualist account of knowledge-how (as described in $§ 1$ ) has a problem with epistemic defeat across its main modalities (psychological vs. normative and undercutting vs. rebutting). If intellectualism were correct, and knowledge-how were a species of knowledge-that, we should expect that the same mechanisms of defeat that undermine propositional knowledge would undermine knowledge-how. But that is not the case, as we have shown in $\S 2$, with different variations on GRENADE FACTORY. Second, we have filled a lacuna in the existing literature by showing in $\$ 3$ how an anti-intellectualist account of knowledge-how may have a positive answer to the issue of how knowledgehow stands subject to epistemic defeat. An understanding of knowledge-how centred around abilities rather than propositional attitudes may account for different situations where knowhow seems to be genuinely defeated, a problem that we have faced via appeal to Sosa's SSS account. In this sense, we have shown that there are situation defeaters (both normative and stative), shape defeaters (again, normative and stative), and seat defeaters (in this case, stative but not normative), and that each of these categories may either inhabilitate or downgrade the agent's know-how, as we have shown in $\$ 4 .{ }^{43}$ In contrast to what the intellectualist would hold, we have shown that in each of these situations, the reason why the knowledge-how is defeated is different from the appearance of some new information that undercuts the agent's justification for her beliefs, or that rebuts the truth of those beliefs. What makes a difference though is that in each of those cases of genuine know-how defeasibility there is some new feature, either of the agent's practical environment, of his transitory shape, or of the innermost seat of his skill, that actually imperils agent's capacities, preventing them from being manifested in the set of the relevant circumstances where she is expected to succeed. ${ }^{44}$ It

42 Thanks to a referee at Philosophy and Phenomenological Research for prompting discussion on this point.

43 One issue we have not taken a stand on in this paper is a metaphysical one; namely, whether states of know-how just are abilities (so that to defeat $S$ 's ability to $\varphi$ just is to defeat $S$ 's knowledge how to $\varphi$ because these are one and the same state of $S$ ), or whether they are distinct states which entails the possession of these abilities (so that if one defeats $S$ 's ability to $\varphi$ one defeats $S$ 's knowledge how to $\varphi$ because, necessarily, one can know how to $\varphi$ only if one possesses the ability to $\varphi$ ). As we see it, we needn't commit here (in light of our dialectical aim) on this metaphysical point, though it is an interesting and important one for an overall anti-intellectualist analysis of knowledge-how to address. The authors have recently elsewhere (i.e., Carter \& Navarro 2017) developed such an analysis which commits to, and defends, the second of the two foregoing interpretations, though we think it goes beyond what we can do to present this view here. Thanks to an anonymous referee at Philosophy and Phenomenological Research for querying this point.

44 The authors would like to thank Modesto Gómez Alonso, Emma C. Gordon, Josh Habgood Coote and Pablo Rey Blanco for helpful discussion and two anonymous referees at Philosophy and Phenomenological Research for very useful comments on a previous version of this paper. Research for this paper was supported by the Spanish MINECO (Ministerio de Economía y Competitividad) via research Grants FFI2014-51811-P and FFI2015-67569-C2-1-P, and by the V Plan Propio de Investigación of the Universidad de Sevilla. 
remains to be explained how the particular phenomenon of epistemic defeasibility may be integrated into a full-blown anti-intellectualist analysis of knowledge-how-a project the authors are undertaking to develop in future work.

\section{References}

Alston, William P. 2005. Beyond Justification: Dimensions of Epistemic Evaluation. Cambridge University Press.

Austin, John L. 1979. 'Ifs and Cans', Philosophical Papers, Clarendon Press. Reprinted from Proceedings of the British Academy, 1956.

Bengson, John and Moffett, Marc A. 2011. 'Two Conceptions of Mind and Action: Knowledge How and the Philosophical Theory of Intelligence', In John Bengson and Marc Moffett (eds.), Knowing How. Oxford University Press 3-55.

Bergmann, Michael. 1997. 'Internalism, Externalism and the No-Defeater Condition'. Synthese 110 (3): 399-417. https://doi.org/10.1023/a:1004993228686.

2005. 'Defeaters and Higher-Level Requirements'. The Philosophical Quarterly 55 (220): 419-36.

Carter, J. Adam and Bolesław, Czarnecki (2016). Extended Knowledge How'. Erkenntnis 81 (2): 259-273.

— and Jesús, Navarro. 2017. 'Towards an Anti-Intellectualist Analysis of KnowledgeHow'. Manuscript.

and Poston, T. 2017. A Critical Introduction to Knowledge-How. Bloomsbury.

— and Duncan, Pritchard. 2015a. 'Knowledge-How and Cognitive Achievement'. Philosophy and Phenomenological Research 91 (1): 181-99.

_ 2015b. 'Knowledge-How and Epistemic Luck'. Noûs 49 (3): 440-53.

2015c. 'Knowledge-How and Epistemic Value'. Australasian Journal of Philosophy 93 (4): 799-816.

Cath, Yuri. 2011. 'Knowing How Without Knowing That', Knowing How: Essays on Knowledge, Mind and Action, eds. John Bengson and Marc Moffett, Oxford: Oxford University Press: 113-35.

2013. 'Regarding a Regress', Pacific Philosophical Quarterly, 94 (3): 358-388.

Choi, Sungho. 2006. 'The Simple Vs. Reformed Conditional Analysis of Dispositions.' Synthese 148 (2): 369-79.

2008. "Dispositional Properties and Counterfactual Conditionals." Mind 117 (468): 795-841.

Chrisman, Matthew. 2008. 'Ought to Believe'. The Journal of Philosophy 105 (7): 34670.

Dreyfus, Hubert L. 2007. 'The Return of the Myth of the Mental', Inquiry 50, 352-365.

Engel, Pascal. 2007. 'Belief and Normativity', Disputatio, 2(23): 1-25.

Glick, Ephraim. 2015. 'Practical Modes of Presentation', Noûs, 49: 538-559. https://doi. org/10.1111/nous. 12052

Goldberg, Sanford C. 2015. 'Should Have Known'. Synthese, January, 1-32. https://doi. org/10.1007/s11229-015-0662-z.

Goldman, Alvin. 1999. Knowledge in a Social World. Clarendon Press Oxford.

Greco, Daniel. 2014. 'Could KK Be OK?' The Journal of Philosophy, 111(4), 169-197.

Greco, John. 2012. 'A (Different) Virtue Epistemology', Philosophy and Phenomenological Research, 85(1), 1-26. 
Hawley, Katherine. 2003. 'Success and Knowledge-How, American Philosophical Quarterly, 40(1), 19-31.

Hornsby, Jennifer. 2011. 'Ryle's Knowing-How, and Knowing How to Act', In John, Bengson and Marc, Moffett (eds.), Knowing How. Oxford University Press, 80-98.

Lackey, Jennifer. 1999. 'Testimonial Knowledge and Transmission'. The Philosophical Quarterly 49 (197): 471-90. https://doi.org/10.1111/1467-9213.00154.

2005. 'Memory as a Generative Epistemic Source'. Philosophy and Phenomenological Research 70 (3): 636-58.

2014. 'Socially Extended Knowledge.' Philosophical Issues 24 (1): 282-298.

Maier, John. 2014. 'Abilities', The Stanford Encyclopedia of Philosophy (Fall 2014

Edition), Edward N. Zalta (ed.), URL = <http://plato.stanford.edu/archives/fall2014/ entries/abilities/>.

Mele, Alfred. 2002. 'Agents' Abilities', Noûs, 37: 447-470.

Navarro, Jesús. 2015. 'No achievement beyond intention', Synthese 192(10): 3339-3369. Under review. 'Bridging the Intellectualist Divide'.

Nöe, Alva. 2005. 'Anti-Intellectualism', Analysis, 65(288):278-90.

Papineau, David. 2015. 'Choking and the yips', Phenomenology and the Cognitive Sciences 2, 295-308.

Pavese, Carlotta. 2015. 'Practical Senses', Philosophers' Imprint 15 (29): 1-25.

— Forthcoming. 'Know How and Gradability', Philosophical Review.

Pollock, John L. (1970). 'The Structure of Epistemic Justification', American Philosophical Quarterly 4: 62-78.

and Cruz, Joseph. 1986. Contemporary Theories of Knowledge. Rowman and Littlefield.

Poston, Ted. 2009. 'Know-How to Be Gettiered?' Philosophy and Phenomenological Research 79(3): 743-47.

— Forthcoming. 'Know-how to Transmit Knowledge?', Noûs.

Pritchard, Duncan. 2010. 'Relevant Alternatives, Perceptual Knowledge and Discrimination'. Noûs 44 (2): 245-68.

Sacks, O., Wasserman R. L., Zeki S. and Siegel R. M.. 1988. 'Sudden Colour Blindness of Cerebral Origin', Society for Neuroscience Abstracts 14, p. 1251. 1988.

Schiffer, Stephen. 2002. 'Amazing Knowledge', Journal of Philosophy, 99(4):200-202.

Searle, John. 1969. Speech Acts. Cambridge University Press.

Shah, Nishi. 'How Truth Governs Belief.' Philosophical Review 112(4): 447-482.

Shah, Nishi and J. David Velleman. 'Doxastic Deliberation.' Philosophical Review 114 (4): 497-534.

Snowdon, Paul. 2004. 'Knowing How and Knowing That: A Distinction Reconsidered', Proceedings of the Aristotelian Society 104 (1): 1-29.

Sosa, Ernest. 1991. Knowledge in Perspective: Selected Essays in Epistemology. Cambridge University Press.

2010. 'How Competence Matters in Epistemology', Philosophical Perspectives, 24 (1), 465-475.

2015. Judgment and Agency. Oxford University Press.

Stanley, Jason. 2010. 'Knowing (How)', Nous 45(2), 207-38.

2011. Know How. Oxford: Oxford University Press.

Stanley, Jason and Timothy, Williamson. 'Knowing how', The Journal of Philosophy (2001): 411-444. 
Stinear, Cathy M., Coxon, James P., Fleming, Melanie K., Lim, Vanessa K., Lim, Vanessa K., Prapavessis, Harry and Winston, D. Byblow. (2006). 'The Yips in Golf: Multimodal Evidence for Two Subtypes'. Medicine and Science in Sports and Exercise 38, no. 11 (2006).

Sudduth, Michael. 2008. 'Defeaters in Epistemology'. Internet Encyclopedia of Philosophy.< http://www.iep.utm.edu/ep-defea/>.

Wedgwood, Ralph. 2002. 'The Aim of Belief.' Noûs 36 (16): 267-297.

Wilson, Robert A. and Foglia, Lucia. 2016. 'Embodied Cognition', The Stanford Encyclopedia of Philosophy (Winter 2016 Edition), Edward N. Zalta (ed.), forthcoming URL = <http://plato.stanford.edu/archives/win2016/entries/embodiedcognition/>.

Wittgenstein, Ludwig. 1953, Philosophical Investigations, translated by G. E. M. Anscombe, Oxford: Blackwell, 3rd edition, 1967. 